\title{
AC 2012-5292: ADVISING ENGINEERING STUDENTS TO THE BEST PROGRAM: PERSPECTIVE, APPROACHES, AND TOOLS
}

\section{Dr. Narciso F. Macia P.E., Arizona State University, Polytechnic}

Narciso F. Macia is an Associate Professor in the Department of Engineering Technology, at Arizona State University, Polytechnic campus. Prior to accepting his present position with ASU, he founded Control Systems Innovation, Inc., an engineering consulting and product development firm, in which he continues to be active. Macia received his B.S. and M.S. degrees in mechanical engineering in 1974 and 1976 from the University of Texas, Arlington, and his Ph.D. in electrical engineering from Arizona State University in 1988. He is a registered Professional Engineer in the state of Arizona. He is a member of ASME and ASEE. He is the holder of three patents and more than 36 publications. He has co-authored a book on modeling and control of dynamic systems.

\section{Dr. Robert W. Nowlin, Retired}

Robert W. Nowlin is retired but serves as an Adjunct Professor at Mesa Community College and a faculty associate at Arizona State University. He received his Ph.D.E.E. from Texas Tech University in 1975, a M.S.E.E. from San Diego State University in 1969, and a B.S.E.E. degree from the University of Washington in 1963. From 1996 to 2000, he was the Department Chair of the lectronics and Computer Engineering Technology Department at Arizona State University East. From 2000 to 2007, he served as a Staff Engineer at Acoustic Technologies Inc. in Mesa, Ariz. He holds one patent and is the author and/or co-author of numerous papers. He is a senior, life member of IEEE and a member of ASEE. 


\section{Advising Engineering Students to the Best Program: Perspective, Approaches and Tools}

\section{Introduction}

Our present era is characterized by an almost an infinite number of choices, ranging from ice cream flavors to vehicles. The situation is no different for those pursuing careers in engineering programs: classical engineering, multidisciplinary engineering or engineering technology; 4year and 2-year programs; not to mention the plethora of areas within these programs.

Many departments try to fit the incoming student into their particular mold. They assume that if a student is at their doorstep, their department or program can provide the best educational environment for the student. Many times this works well, but often the student is placed in a suboptimal environment because the student's unique characteristics and aspirations are not considered in creating the best possible educational program-student match. All of us in educational institutions have an ethical obligation to help the student discover which program is best for them.

This paper offers a graphical representation for capturing the characteristics of a given program, that can be used for contrasting various types of 4-year, engineering programs, and also in providing guidelines for optimal student-program matching. It attempts to provide a tool that is partial solution to the common problem of students matriculating into a sub-optimal program match. The proposed graphical representation shows simultaneously the distribution of practical ability (skill) and theoretical knowledge (knowledge) of a particular program on the vertical axis, versus the multiplicity of subject covered in the program on the horizontal axis. Even though there is a connection between skill and knowledge, this connection is not guaranteed, nor is it well defined or understood. For instance, one might know how and where to use sugar (skill) but at the same time have no idea of how sugar is produced (theoretical knowledge). Also, one might know how to describe the chemical and physical reaction that arrests material degradation in a galvanized metal (theoretical knowledge) but have never galvanized a part.

In summary, this paper has three goals:

1. Provide some ethical motivation for university administrators to put in place programs that help a prospective student choose a degree program that matches his/her interests, academic skills and immediate and long-term career plans.

2. Present a graphical representation that can be used to contrast the various characteristics of engineering programs that can be used as a vehicle for comparing the pedagogical approaches favored in these educational programs. This diagram can be useful for educators in comparing the differences and similarities between their programs. It can also be used by recruitment personnel for presenting to the prospective student the differences and similarities among the programs that they are considering.

3. Propose the introduction of course that would help the student decide the best path for them. This could take place in their first semester, or during the summer, and focus on creating a match between the existing programs and the student's aspirations, strengths and talents. It would help the students understand which of the branches of engineering would be most conducive to their 
success; as a solution to the common problem of students enrolling in a sub-optimal program match.

\section{Overview of Engineering-Type Programs}

There has always been a variety of engineering type programs in the United States that encompass the continuum of needs found in industry and academia. Some of the programs have been created to address perceived voids in employment needs spectrum.

Classical engineering education ( also called discipline-based engineering programs ) has a mission to produce graduates that have the ability to create new products for the marketplace, perhaps using principles that have not been in regular use (often in the research and development stage). Often these programs have a very theoretical focus. This is due in part to the discipline's hope that a large portion of its graduates will choose to pursue graduate studies. In these cases, the students' preparation for research is of primary importance. However, graduates from these programs often end up doing jobs that they could do without the highly theoretical education that they have received. Common names for these programs include Mechanical Engineering, Electrical Engineering, Industrial Engineering, etc.

Engineering technology, on the other hand, has a more hands-on, applied focus. Its graduates work in all aspects of engineering, even though a large portion end up in the manufacturing and test systems area. In reality, the bachelor's degree provides an initial credential for entering industry. Once the graduate finds initial employment, the graduate has the ability to migrate toward a position and type of work that attracts him or her most. Having said that, it must be also recognized that an engineering technology graduate is likely to encounter some difficult time migrating into research, even some have done it successfully.

In addition, there are several programs around the United States that also offer a style of engineering education different from classical engineering or engineering technology. They are often called general or multidisciplinary engineering. A paper presented at this conference [1] revisits a research study published about ten years ago, which compares general engineering programs in the United States [2]. Examples of universities in this category include Harvey Mudd, Swarthmore, Smith College and ASU Polytechnic. Many of these programs try to impart a classical education to their graduates, in a more focused manner that by simply requiring the students to take a set of courses in the humanities.

At ASU Polytechnic offers a multidisciplinary engineering degree, in which students take the same coursework during the first two years, and from then on, the student begins to pursue their chosen area of concentration. In addition, every semester, the students take a three- to 4semester-hour project course, where they work in teams to design products and solve realistic engineering problems. In addition, all the other courses are broken into 1 credit-hour "modules" [3].

\section{Ethical Obligation}

All of us in educational institutions have an ethical obligation to help the student discover which program is best for them. The authors believe that a proper choice by the students facilitates a successful educational career (which often colors their professional career). Similarly, incorrect 
choice often means continual struggle, and sometime leaving the educational program before completion.

It is easy to see how the adoption of such a discernment process is easily overpowered by other factors, such as: pre-determined quotas of incoming students, suspicions that other departments will not follow the same approach, lack of support from high level administration, or simply being too busy to deal with another issue. However, the authors believe that the significant and long lasting positive (or negative) influence on the student's immediate and future life warrants such an inquiry.

\section{Existing Graphical Models}

One area that is clouded with confusion and misunderstanding is the differences and similarities between classical engineering, multidisciplinary engineering and engineering technology. This is especially true in the case when comparing 4-year undergraduate programs. In an effort to tackle this problem, engineering educators have developed graphical techniques and elevatorspeeches for differentiating the different types of programs. One such approach is shown in Figure 1 (source unknown). The purpose of showing this illustration is to introduce a particular graphical vehicle itself, rather than the confirm employment distribution shown in it (which may be difficult to achieve consensus on).

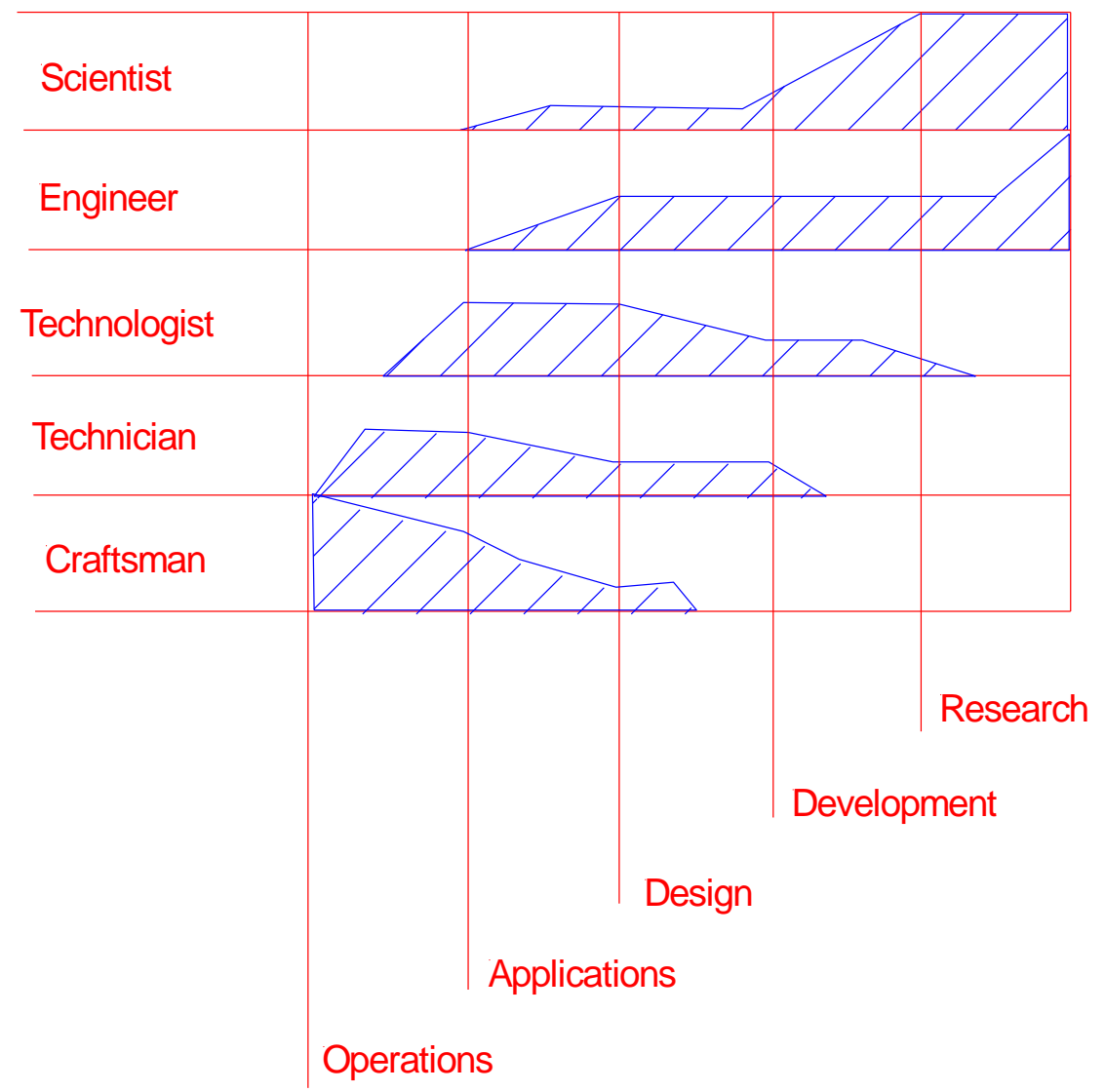

Figure 1: Graphical vehicle used to compare educational background in various technical professions. (Source: unknown) 
Another similar device has been developed by ASME, as shown here in Figure 2 [4].

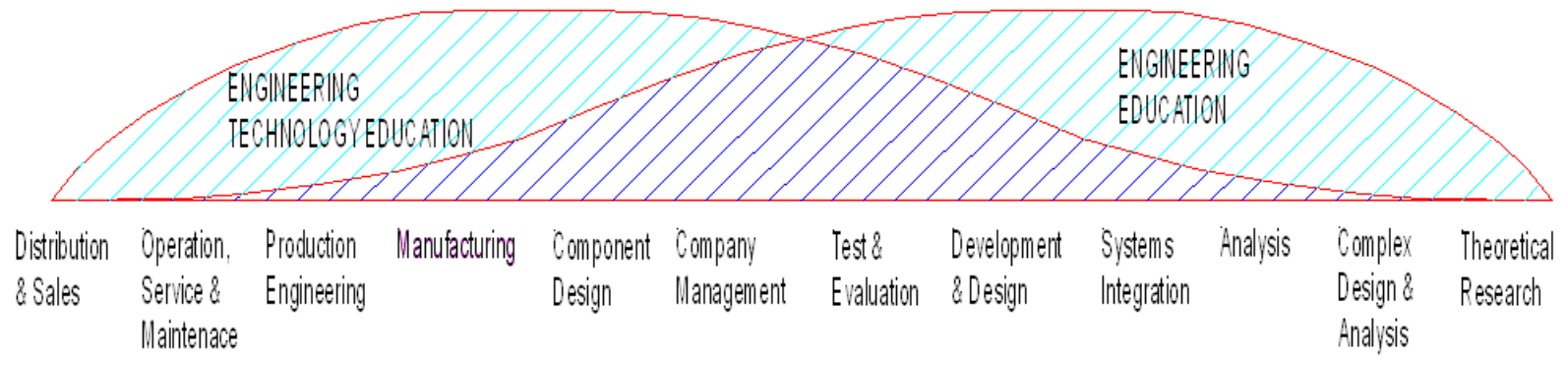

Figure 2: Graphic used by the American Society of Mechanical Engineers for comparing engineering and engineering technology.

\section{Expressing Competency}

Prior to introducing the graphical model proposed in this paper, one of its most important components, competency, is introduced. A very important qualifier associated with graduates in a given program is competency. Employers certainly want to hire graduates who are competent. Although competency, skill and knowledge are often used in the same sentence [5], (or certainly, the last two) Albert McHenry [6], is the first person in the author's knowledge, to have related them using a mathematical form, by defining competency as the algebraic sum of skill and knowledge, or:

$$
\text { Competency }=\text { skill }+ \text { knowledge }
$$

Notice that even though there is typically a connection between skill and knowledge, it is not guaranteed (nor is it well defined or understood). For instance, one might know how and where to use sugar (skill) but at the same time have no idea of how sugar is produced (theoretical knowledge). Also, one might know how to describe the chemical and physical reaction that arrests material degradation in a galvanized metal (theoretical knowledge) but have never seen a part being galvanized.

Now a more mathematical definition of competency is proposed. It enhances the previous definition, and re-expresses it by the formula:

$$
\text { Competency }=\int(\text { skill }) d B+\int(\text { knowledge }) d B
$$

where the variable of integration, $B$, represents breadth of different fields. This implies that true competency is composed of skill and knowledge in a multiplicity of subjects. This relationship can be represented graphically with a vehicle that captures the mix of skill and knowledge in each of the topics covered. In other words, a competent individual has a unique mix of both skill and knowledge over a multitude of subjects.

\section{Proposed Graphical Model}

This concept presented in the previous section states that true competency is comprised of skill and knowledge in a multiplicity of fields. The graphical representation that attempts to capture it is the main idea of this paper. Consider two tasks: measuring the characteristics of a signal using an oscilloscope, and designing a digital filter. One could represent these two tasks graphically, in terms of the skill and knowledge required, as is shown in Figure 3. This representation can then 
be expanded to include the educational effort behind imparting the required skill and knowledge for the students to perform these tasks.

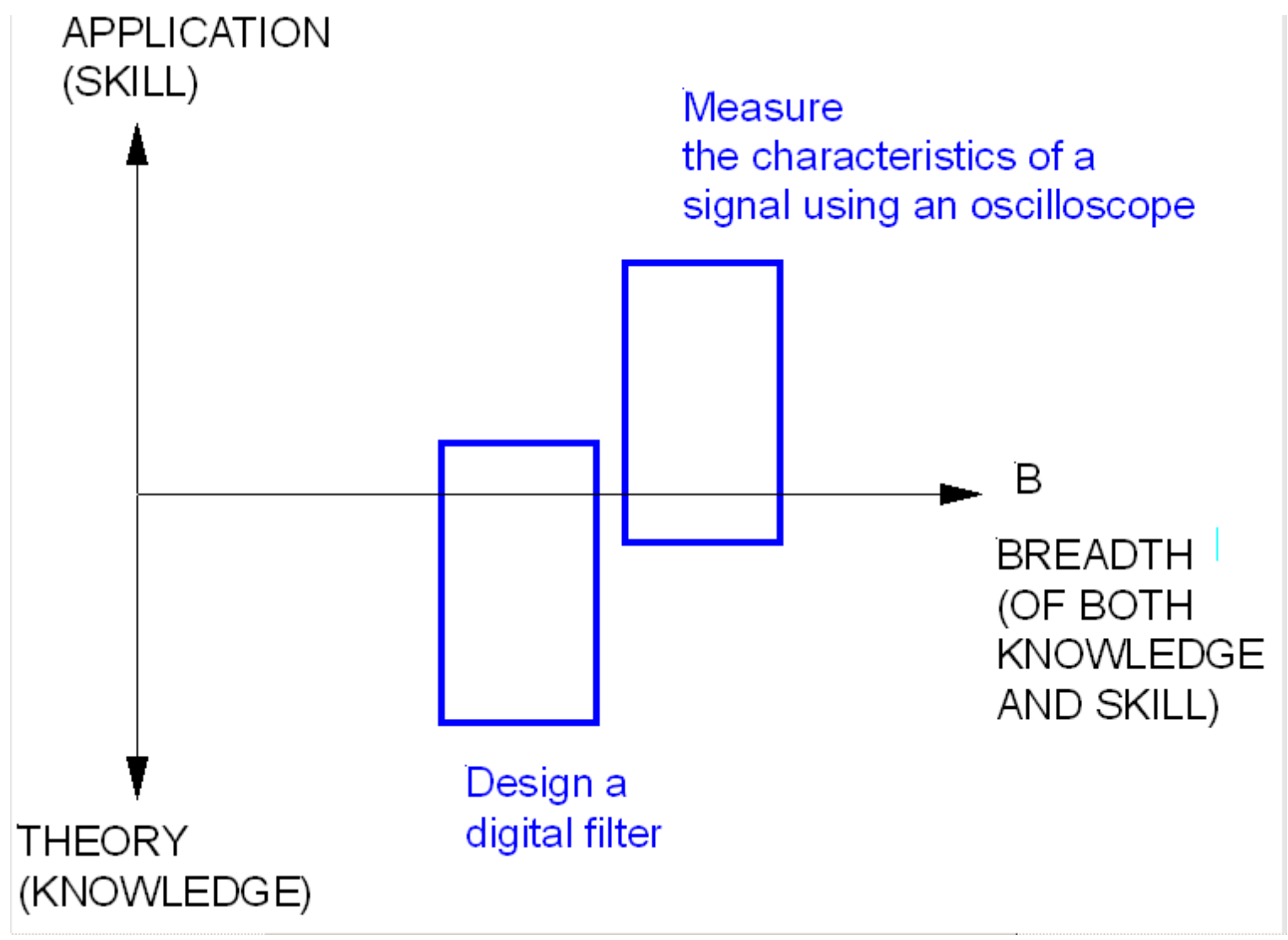

Figure 3: Graphical representation indicating the skill-knowledge mix required to perform two different tasks.

The vertical axis of this graphical model represents the degree of "skill" and "knowledge" necessary to do the task. This does not seek to force knowledge and skill into opposition, but rather to help classify two distinct but complementary parts of acquiring competency. Units for this axis could be in hours dedicated in lecture-type instruction and laboratory-demonstration activities. The horizontal axis of this graph represents different areas addressed during instruction, namely the breadth of study areas.

The graphical model can be extended to capture the multitude of teaching/learning environments used by a department in educating their students. This can be adapted by any university, and with a small amount of data collection and analysis can show an accurate view of how their various engineering programs are similar and/or different regarding the mix of laboratory experiences, application-based learning and theoretical learning. Figure 4 shows a possible comparison of three programs. Again this particular diagram is not the result of an objective effort, obtained by tabulating the number of hours used in the various modalities of instruction (i.e. laboratory, lecture, group-work, etc.). This diagram is of a more anecdotal nature, and one used for an actual comparison would depend on the particular programs at a given institution. 


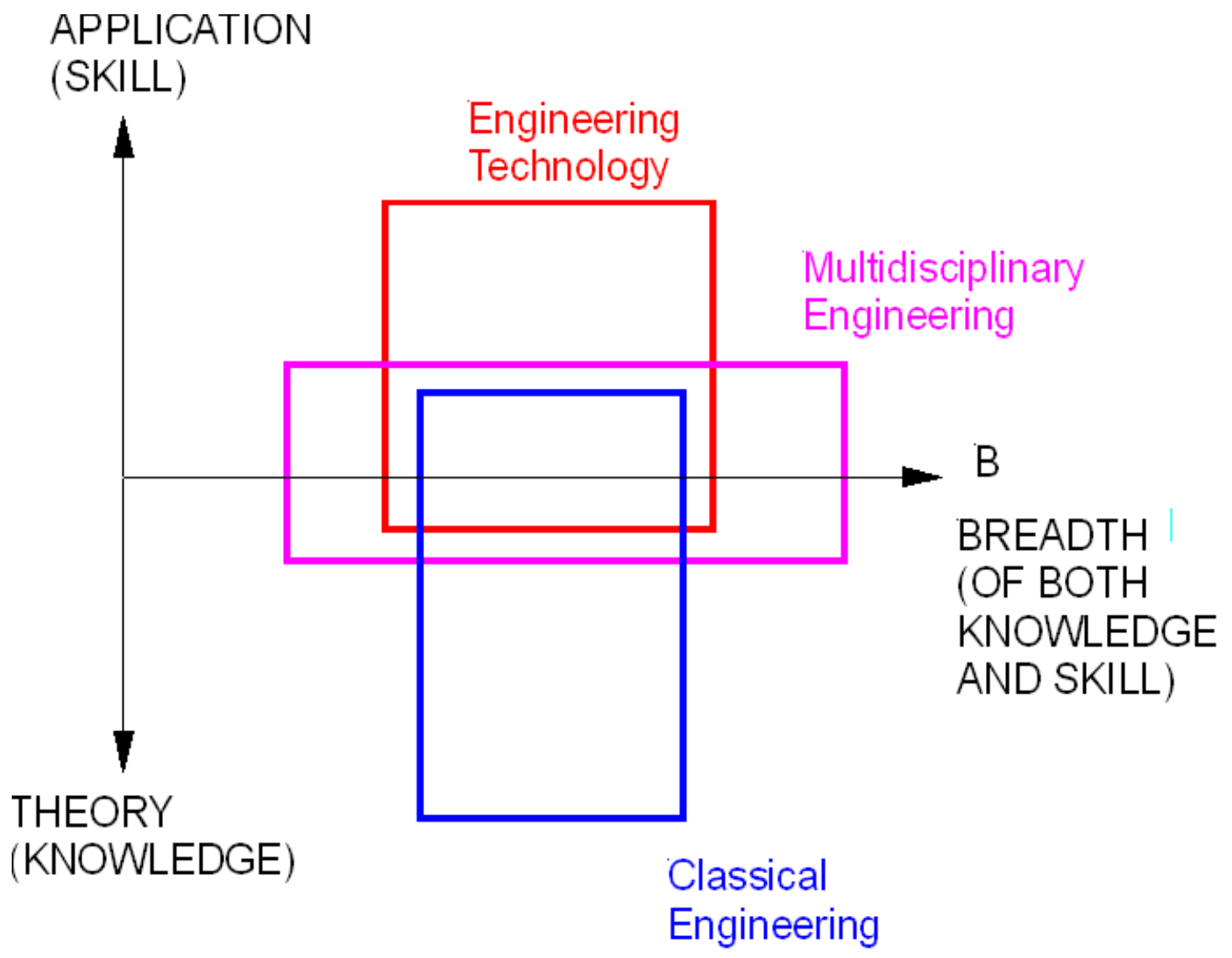

Figure 4: Comparison of three programs at a given university.

An alternative form of this same graphical model, that may prove more insightful for some students who are interested in obtaining a general overview, and would include various faculties of engineering, departments, programs, degrees, or majors down the vertical axis. This would be able to show the differences between how theoretical- or application- oriented a given type of engineering program is. This graph can be easily populated, for example, by degrees. Each degree has a certain number of hours of classroom instruction and a certain number of hours of lab/project time. These can easily be found either by looking at credit hour ratios or more indepth by analyzing each class to see what ratio of time is spent on each learning modality. Ideally time spent on "homework" for each class would be included, but it is impossible to standardize and so would be better left out. The results are summed for each degree, aligned next to each other and the result is an easily visualized comparison of the engineering degree options, as done in Figure 5. Again, these illustrations are illustrations purposes only, since they are not derived from actual hard data. 


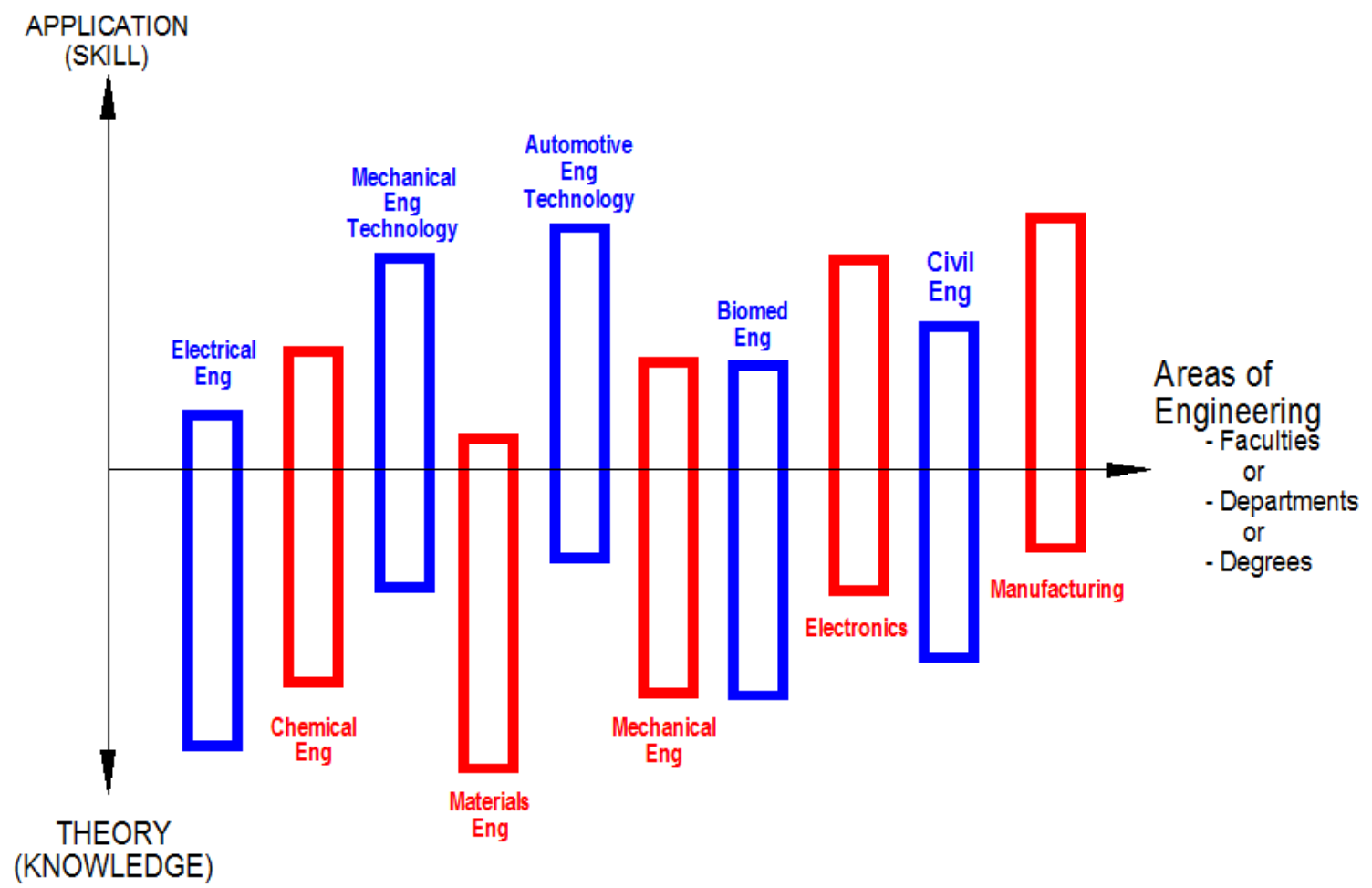

Figure 5: Graphical skill-knowledge diagram for various disciplines.

\section{Helping Educators Contrast Engineering Programs}

This graphical instrument can be used by faculty members who work at an institution that offers more than one engineering program. It would provide a way for contrasting their departments, so that they can bring into their department (or send to the other department) incoming students whose goals match the goals of the department. It is assumed that these instructors share a collegial attitude toward each other and their respective programs, and have an earnest desire to help students find the best program fit.

This graphical representation can also facilitate communication among practitioners (industry) and educators in the field, by helping the student find the ideal educational path that will fulfill their professional goals, namely what type of education will prepare them best for the kind of job they want to do upon graduation.

\section{Helping Students Find the Best Fit for Them}

In reality, a large portion of the incoming students are not really sure that the field that they have chosen is the optimal for them. We recommend that students participate in a program during their first semester that would address this issue. They would explore their aspirations, strengths and talents and compare that with the characteristics of the program that they are considering. Such course is completely voluntary. Students who feel very sure of their chosen career path should not be required to take the proposed course. It would help the students understand which of the branches of engineering would be most conducive to their success; as a solution to the common problem of students enrolling in a sub-optimal program match. 
All students who enter a university with the goal of pursuing a degree in engineering can be given a survey to discover their aptitude and career preference. This survey would be reviewed by advisors and students would be advised in most suitable direction for them. The survey would be given by the admitting department, and electronically graded, with the purpose of eliminating any possible biases. If ACT and SAT scores are on file, they will also be used to assist in the decision. If the survey showed that the student has a clear idea of what they want to do and demonstrates the aptitude for it they would be encouraged to pursue the field of their choice. However, if the student seems unapt for the educational path that they initially express desire for, or if they are unclear as to what they aspire to in their career, the advisors would recommend that they take a one-semester course focusing on helping the student discover their aspirations, strengths and gifts. At the end of this one-semester course the student, in collaboration with the instructor, should be able to better decide which program is the best fit for them. A simple model here for that advising path is shown in Figure 6.

Lastly, the implementations of such a model for helping engineering students find the best program-match must be driven by higher-level university personnel. Otherwise, chances are that little progress will take place if it is initiated and proposed at a particular department only.

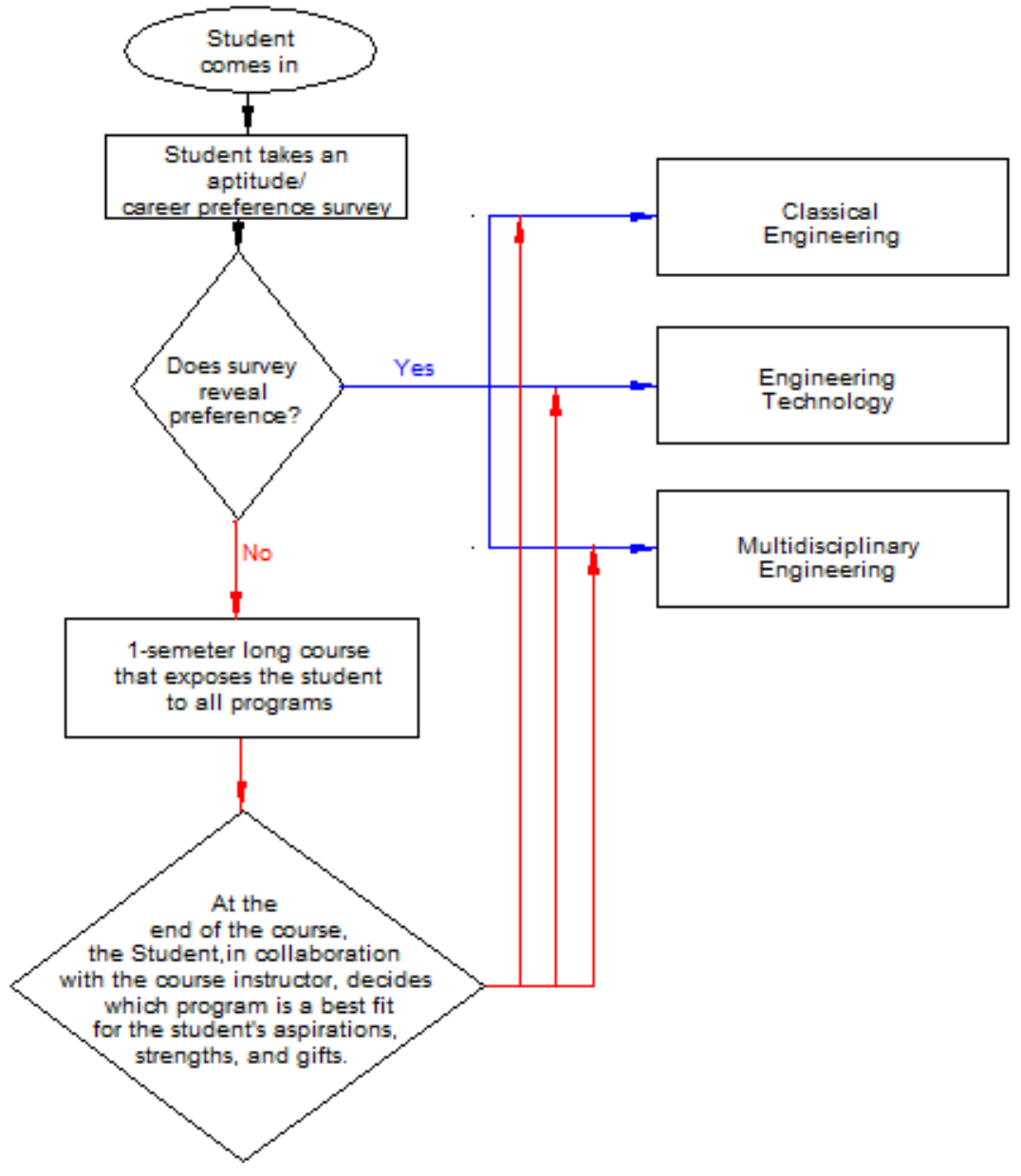

Figure 6: Educational Path Choice Flowchart 
Another method for implementing this method could take place in the context of a Autumn Term [7], a 4-week long (or less) "intensive semester", that precedes the fall semester, and whose goals is to help freshman students transition successfully from a high-school mindset to a college one.

\section{Possible Application to Large Departments Having Significant Variations in Their Students' Learning Styles}

The thinking preference of students has been documented using the Herrmann Brain Dominance Profile (HBDP) [8]. These authors have shown that this preference shifts as a result of the paradigm shift occurring as society changes (as time progresses and the prevalent culture changes). These authors have also shown that students in different fields of engineering (for example chemical engineering and computer science) exhibit different thinking preferences. Their data also shows variation of students' thinking preferences that are pursuing the same field. We believe that there is a connection between a student's thinking style and his/her favored/preferred learning style.

This provides an opportunity to serve students better. Assuming that multiple sections of the same class are necessary to serve the student body, why not have some sections that use a more laboratory-based instruction while the rest of the sections use more theoretical/abstract approach. A very important requirement of this suggestion is to institute clearly defined objectives for both approaches, and to have assessment mechanism in place to ensure that it is really happening. The proposed graphical tool described in this paper could be used to assist in contrasting the various approaches that will be used in the educational process.

\section{Application to Employee Selection and Team Building}

It is a generally accepted principle that the more diversity present in a team, the more likely that a solution will be found. Also, chances of discovering the optimal solution are enhanced as the number of viable solution candidates increases. Figure 7 represent the skill-theory (anecdotal) coverage that results when an engineering graduate and an engineering technology graduate work as a team. This graphical representation communicates that the engineering student educational background covers a broader spectrum of topics, while the engineering technology students has his skill-knowledge contour in a more focused area, yet, he has more practical abilities than the engineering graduate. However most importantly, their combined coverage is much larger than by each of them working alone. In addition, by working with the other team member who has a different background, both of them may gain new insight, that they did not otherwise have prior to their interaction. 


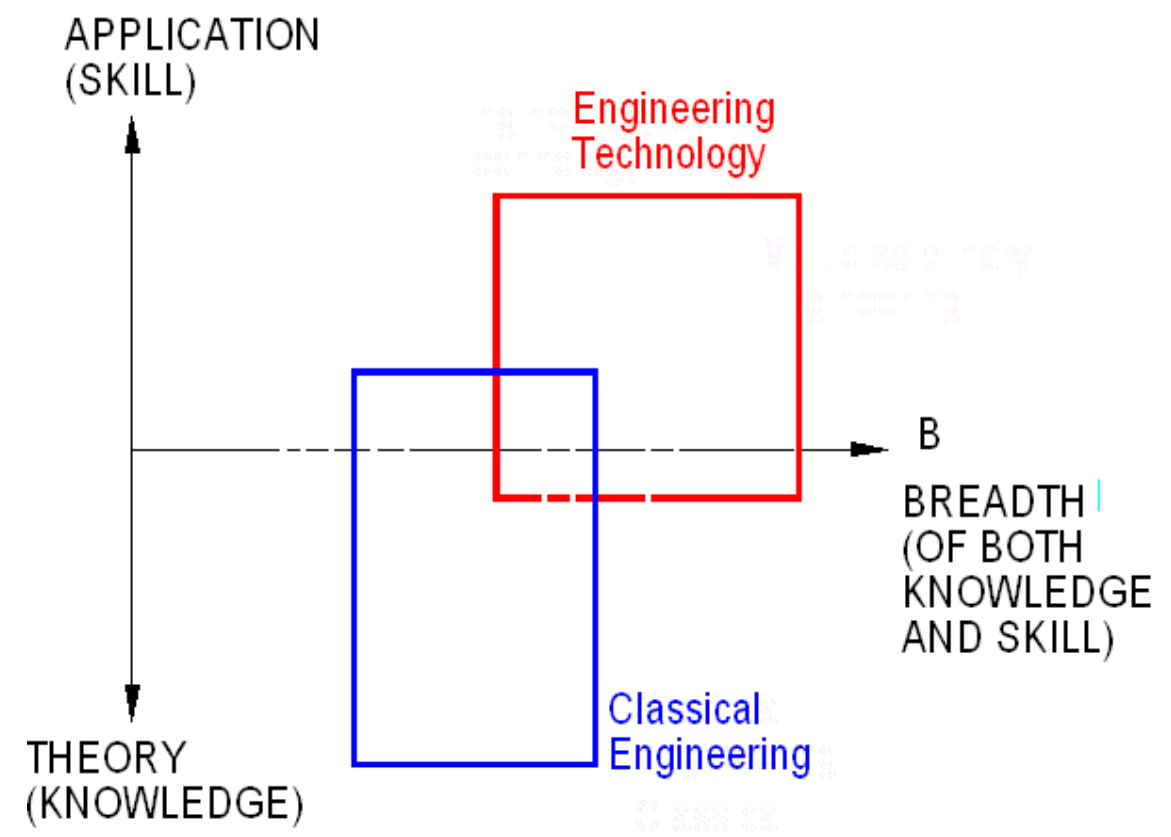

\section{Figure 7: Application of graphical tool help determine complimentary of two members of a team with different educational backgrounds.}

\section{Conclusions}

It is clear that institutions have an ethical obligation to serving the students who come to them as best as they possibly can. As centers for learning they must make every effort to help students discover the best program match for their aspirations and career goals, and also that best fits their strengths and desires. The graphical tool presented in this paper provides a useful tool to help educators in guiding aspiring engineers find the optimal educational program fit for them.

\section{References}

[1] Grondin, R., "Newberry and Farison Redux: A survey of general engineering", Proceedings, 2012 ASEE Annual Conference, ASEE, San Antonio, TX.

[2] Newberry, B., and Farison, J. "A Look at the Past and Present of General Engineering and Engineering Science Programs" Journal of Engineering Education , 217-226 (2003).

[3] Multidisciplinary Engineering at Arizona State University Polytechnic campus. https://technology.asu.edu/degrees/UGTS/TSEGRBSE

[4] Marketing brochure, 2011, American Society of Mechanical Engineers, New York, N.Y.

[5] Egbu, Charles O., "Skills, knowledge and competencies for managing construction refurbishment works", Construction Management \& Economics, January 1999.

[6] Albert L. McHenry, Ph.D., is Professor Emeritus at Arizona State University. Personal communications.

[7] Eckerd College, St. Petersburg, Florida.

[8] Lumsdaine, Monika and Lumsdaine, Edward. "Thinking Preferences of Engineering Students: Implications for Curriculum Restructuring”, Journal of Engineering Education, Vol. 84, No.2. 